\title{
Kesalahan Penggunaan Bahasa Indonesia dalam Ruang Publik (Media Luar Ruang) di Kota Baubau
}

\author{
${ }^{1}$ Nazriani, ${ }^{1}$ Arsad \\ Email: nazrianinani@gmail.com
}

\begin{abstract}
The influence of foreign languages, especially English may erode Indonesian authority. Most people feel more confidence and smarter when using English. It is not wrong but contradict to the slogan echoed by the government, "Prioritizing Indonesian, mastering foreign language, and Preserving the language". This research was aimed to study about how the forms of improper use of Indonesian in public spaces in Baubau, and what were the factors that influence the occurrence of these errors. The methods used descriptive qualitative. Technique of collecting the data was used observation and technical documentation record. The result showed that the errors found are errors in placing prefixes and prepositions which still confused-exchange as well as the widespread use of English on shop signs, hotels, salons, and other general instructions. Some of the factors triggering the occurrence of these errors is the lack of knowledge about the use of the Indonesian language properly and correctly, lack of socialization that involve direct community of language users, and the absence of real sanctions for violators language. The results showed that the form were errors in placing prefixes and prepositions are still confused-exchange as well as the widespread use of English on shop signs, hotels, salons, and other general instructions. Some of the factors triggering the occurrence of these errors is the lack of knowledge about the use of the Indonesian language properly and correctly, lack of socialization that involve direct community of language users, and the absence of real sanctions for violators language. Based on the research results form errors found are errors in placing prefixes and prepositions are still confused-exchange as well as the widespread use of English on shop signs, hotels, salons, and other general instructions. Some of the factors triggering the occurrence of these errors is the lack of knowledge about the use of the Indonesian language properly and correctly, lack of socialization that involve direct community of language users, and the absence of real sanctions for violators language.

Keywords: : English Language; Indonesian Languag;, Public Area
\end{abstract}

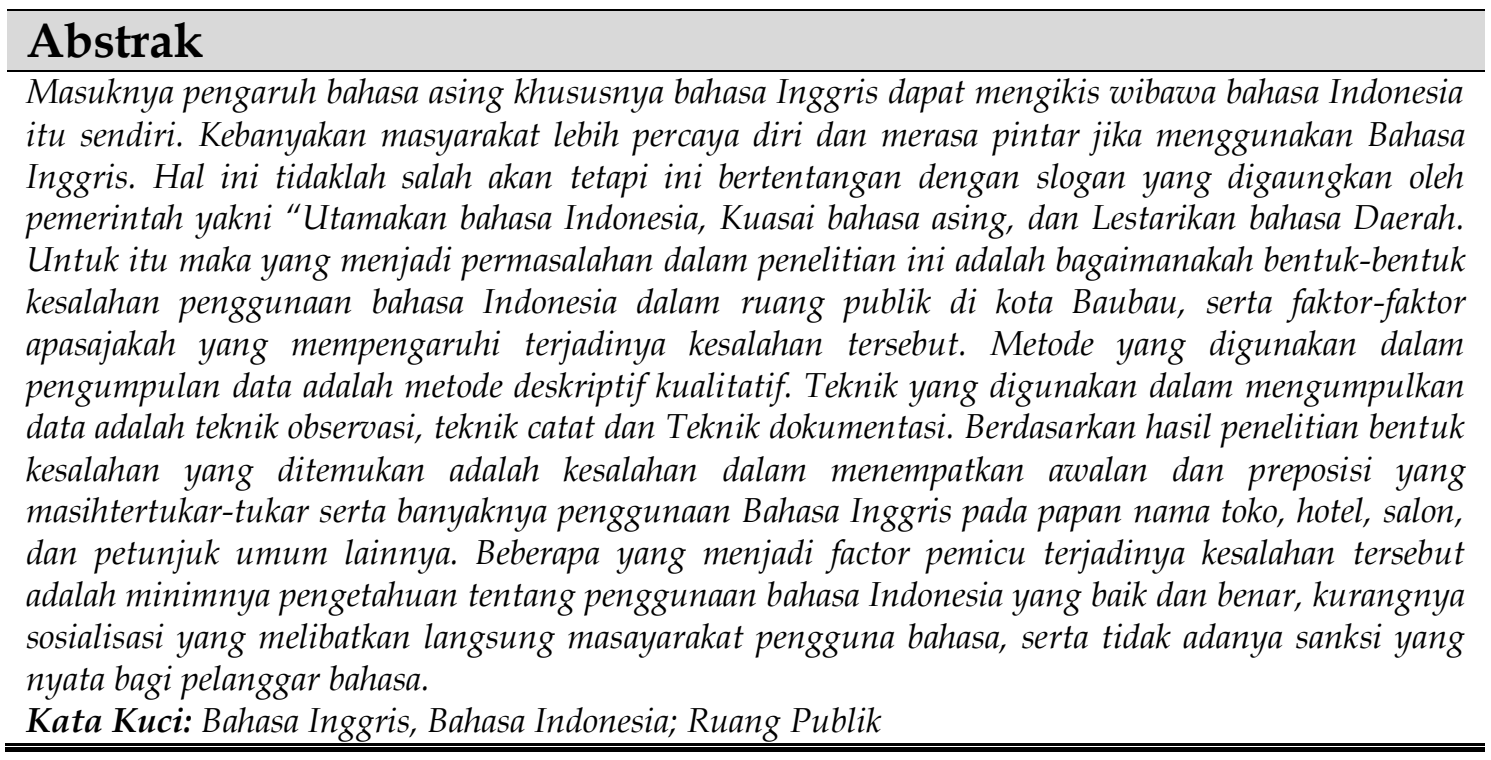

${ }^{1}$ Universitas Muhammadiyah Buton, Indonesia 


\section{PENDAHULUAN}

Sebagai suatu bangsa yang besar, Indonesia mengenali bahasa kedua apa pun, layaknya Malaysia yang menjadikan Bahasa Inggris sebagai Bahasa kedua selain bahasa Melayu. Namun, meskipun Indonesia tidak mengakomodasi bahasa tersebut, bangsa Indonesia tetap sangat terbuka dengan Bahasa asing lainnya, terutama bahasa Inggris (Rahman, 2018)

Masuknya pengaruh bahasa asing khususnya bahasa Inggris dapat mengikis wibawa bahasa Indonesia itu sendiri. Kebanyakan masyarakat lebih percaya diri dan merasa pintar jika menggunakan bahasaInggris. Hal ini tidaklah salah akan tetapi ini bertentangan dengan slogan "Utamakan bahasa Indonesia, Kuasai bahasa asing, dan Lestariikan bahasa Daerah. Jika dibiarkan terjadi tidak menutup kemungkinan suatu saat bahasa Indonesia akan kehilangan identitasnya atau bahkan wibawanya di negaranya sendiri. Bukan hanya terlihat dari komunikasi sehari-hari, akan tetapi dapat juga terlihat dari penggunaan bahasa Indonesia dalam ruang publik, misalnya papan namatoko, salon, hotel, rumah makan, nama kantor pemerintahan, sekolah atau bahkan di perguruan tinggi.

Kota Baubau merupakan salah satu kota yang sedang mengalami masa perkembangan dari berbagaimacam aspek. Taklepas dari persoalan Bahasa kota Baubau memiliki pengguna Bahasa daerah yang berbeda-beda selain Bahasa Wolio. Seiring dengan perkembangan zaman kota Baubau tak luput dari arus gelombang pengaruh Bahasa asing. Hal ini dapat terlihat dari hasil observasi awal masih banyak ditemukan kesalahan penggunaan bahasa Indonesia dalam ruang public seperti penulisan namanama tempat yang masih menggunakan Bahasa asing misalnya laundry, low price, discount up $70 \%$, Barber shop, kesalahan penggunaan kata misalnya di sewakan, di kontrakan, dan masih banyak lagi. Hal ini perlu dibenahi dan perlu disosialisakan agar masayarakat bisa mengetahui bahasa Indonesia yang baik dan benar. Penggunaan bahasa Indonesia yang baik dan benar di ruang publik salah satunya dapat berdampak pada munculnya sikap positif terhadap bahasa Indonesia sendiri. Berdasarkan latar belakang tersebut yang menjadi permasalahan dalam penelitian ini adalah Bagaimanakah bentuk-bentuk kesalahan penggunaan Bahasa Indonesia dalam ruang publik di kota Baubau?, fakator-faktor apa sajakah yang mempengaruhi terjadinya kesalahan penggunaan bahasa Indonesia dalam ruang publik tersebut.

\section{TINJAUAN PUSTAKA}

Peraturan pemakaian Bahasa di ruang publik (media luar ruang) tercantum dalam Undang-Undang Republik Indonesia Nomor 24 Tahun 2009 tentang Bendera, Bahasa, dan Lambang Negara, serta Lagu Kebangsaan khusus dalam pasal 36 ayat (3) yang mengatur bahwa bahasa Indonesia wajib digunakan untuk nama bangunan atau gedung, jalan, apartemen atau permukiman, perkantoran, kompleks perdagangan, merek dagang, lembaga usaha, lembaga pendidikan, organisasi yang didirikan atau dimiliki oleh warga negara Indonesia atau badan hukum Indonesia. Selanjutnya, pada pasal 37 ayat (1) diatur bahwa bahasa Indonesia wajib digunakan dalam informasi tentang produk barang atau jasa produksi dalam negeri atau luar negeri yang beredar di Indonesia, selanjutnya dalam ayat (2) diatur bahwa informasi sebagaimana dimaksud pada ayat (1) dapat dilengkapi dengan bahasa daerah atau bahasa asing sesuai dengan keperluan. Pasal 38 ayat (1) dalam undang-undang tersebut diatur bahwa bahasa Indonesia wajib digunakan dalam rambu umum, penunjuk jalan, fasilitas umum, spanduk, dan alat informasi lainnya yang merupakan pelayanan umum. Selanjutnya, pada 
ayat (2) pasal tersebut diatur bahwa penggunaan bahasa Indonesia sebagaimana dimaksud pada ayat (1) dapat disertai bahasa daerah atau bahasa asing jika dipandang perlu. Segala ketentuan lebih lanjut mengenai penggunaan bahasa Indonesia sebagaimana yang dimaksud dalam undang-undang diatur dalam Peraturan Presiden.

Berdasarkan pernyataan yang tercantum dalam Undang-Undang di atas dapatlah ditarik suatu kesimpulan bahwa pemakain bahasa asing dan bahasa daerah dapat digunakan setelah bahasa Indonesia terlebih dahulu.

\subsection{Kesalahan Berbahasa}

S. Piet Corder dalam bukunya Introducing Applied Linguistik menjelaskan bahwa kesalahan berbahasa adalah pelanggaran terhadap kode bahasa. Pelanggaran ini disebabkan minimnya penguasaan dan pengetahuan terhadap kode. Sedangkan analisis kesalahan berbahasa yaitu suatu cara atau langkah kerja yang biasa digunakan oleh peneliti atau guru bahasa untuk mengumpulkan data atau informasi kebahasaan, mengidentifikasi kesalahan, menjelaskan letak kesalahan, mengklasifikasikan kesalahan dan mengevaluasi tingkat keseriusan kesalahan berbahasa tersebut.

Tolak ukur kesalahan berbahasa biasanya ditentukan berdasarkan ukuran keberterimaan yakni apakah bahasa (ujaran atau tulisan) si pembelajar bahasa itu berterima atau tidak bagi penutur asli atau pengajarnya. Jadi, jika pembelajar bahasa Indonesia membuat kesalahan, maka ukuran yang digunakan adalah apakah kata atau kalimat yang digunakan pembelajar tersebut benar atau salah menurut penutur asli bahasa Indonesia. Ukuran berbahasa yang baik ini adalah ukuran intra bahasa atau intra lingual. Ukuran kesalahan dan ketidak salahan intra bahasa adalah ukuran kebahasaan.

\subsection{Ejaan}

Ejaan yang dimaksudkan dalam tulisan ini adalah aturan mengenai penulisan huruf, penulisan kata, dan pemakaian tanda baca (Arifin dan Tasai, 2010:164). Penggunaan ejaan wajib dipatuhi oleh pengguna bahasa utamanya dalam bahasa tulis. Tujuannya adalah demi keteraturan dan keseragaman bentuk. Hal ini akan berimplikasi pada ketepatan dan kejelasan makna. Hubungan antara ejaan dan pemakai bahasa ibarat rambu lalu lintas yang harus dipatuhi oleh setiap pengemudi. Jika pengemudi mematuhi rambu lalu lintas itu, terciptalah lalu lintas yang tertib, teratur, dan tidak semrawut (Finoza, 2001:13).

Ejaan yang digunakan dalam bahasa Indonesia adalah Ejaan yang Disempurnakan atau yang biasa dsingkat dengan EYD. EYD mulai berlaku pada tanggal 16 Agustus 1972 oleh Presiden Republik Indonesia dan pada tahun 1987 EYD direvisi dengan tujuan untuk memaparkan kaidah ejaan yang lebih luas. Dalam Ejaan bahasa Indonesia yang disempurnakan membicarakan tentang lima pokok aturan yaitu

1. Pemakaian huruf (nama-nama huruf, lafal singkatan dan kata, persukuan, dan penulisan nama diri).

2. Penulisan huruf (penulisan huruf besar/kapital dan penulisan huruf miring).

3. Penulisan kata (kata dasar, kata turunan, kata ulang, dan gabungan kata)

4. Penulisan unsur-unsur serapan (unsur serapan dari bahasa asing)

5. Pemakaian tanda baca (pemakaian tanda titik, koma, titik koma, titik dua, tanda hubung, tanda pisah, tanda elipsi, tanda tanya, tanda seru, tanda kurung, tanda kurung 
siku, tanda petik, tanda petik tunggal, tanda ulang, tanda garis miring, penyingkatan/apostrof).

\subsection{Penggunaan Unsur Asing}

Penggunaan unsur asing sangat berkaitan dengan sikap bahasa. Pada kenyataan di lapangan orang lebih senang menggunakan bahasa asing dari pada bahasa Indonesia baik secara lisan maupun secara tertulis. Penggunaan bahasa atau istilah asing ini secara terusmenerus akan merugikan bahasa Indonesia, sebab orang (baca: masyarakat) secara perlahan akan meninggalkan bahasa Indonesia dan kurang bangga menggunakan bahasa Indonesia lagi. Hal seperti ini sebenarnya tidak perlu terjadi jika ada kesadaran menggunakan bahasa Indonesia. Beberapa istilah asing yang sering didengar dalam kehidupan sehari-hari misalnya shoping-belanja, discountpotonganharga dan masih banyak lagi. Langkah yang dapat dilakukan untuk mengatasi persoalan itu ialah dengan mencarikan padanannya dalam bahasa Indonesia atau menyerap unsure asing itu sesuai dengan kaidah yang berlaku, seperti yang diatur dalam buku Pedoman Umum Pembentukan Istilah dan Pedoman Ejaan Bahasa Indonesia yang Disempurnakan.

\section{METODE PENELITIAN}

Metode yang digunakan dalam penelitian ini adalah metode deskriptif kualitatif. (kualitatif-intrepretatif), yakni menggambarkan suatu fenomena secara alamiah dan apa adanya. Penggunaan metode ini bertujuan untuk mendeskripsikan secara sistematis, faktual dan akurat dengan menggunakan kata-kata atau kalimat dan bukan dengan angka-angka statistik. Semua dikemukakan apa adanya sesuai dengan kenyataan yang ditemukan pada saat penelitian. Sumber data penelitian berasal dari segala macam bentuk kesalahan penggunaan bahasa di ruang publik yang ada di Kota Baubau yang biasa terlihat pada papan nama toko, papan nama hotel, papan nama instansi pemerintahan, spanduk, selebaran, dan baliho yang terpampang di pinggir jalan. Teknik yang digunakan dalam mengumpulkan data adalah teknik observasi, teknik catat untuk mencatat hal-hal yang berkaitan dengan penelitian dan teknik dokumentasi yakni untuk mendokumentasikan data yang diperoleh di lapangan. Teknik dokumentasi berupa foto-foto yang merujuk pada data penelitian. Teknik analisis data yang digunakan dalam penelitian ini adalah teknik yang bersifat deskriptif kualitatif-preskriptif, yaitu mendeskripsikan dan menjelaskan hasil temuan di lapangan dan memberi solusi atau pemecahan atas masalah yang terdapat dalam pemakaian bahasa Indonesia dalam ruang publik di kota Baubau.

\section{HASIL DAN PEMBAHASAN}

Data Kesalahan bahasa Indonesia dalam Ruang Publik/ Media Luar Ruang adalah sebagai berikut:

\section{Data1}

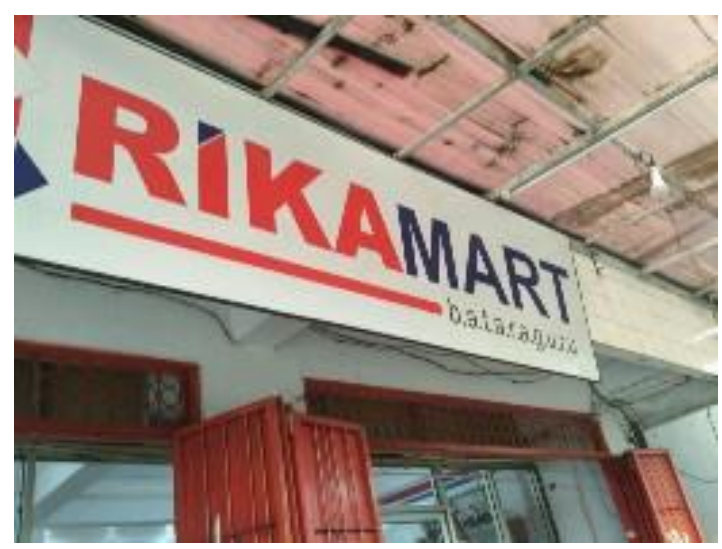

Salah: Rikamart

Benar: Toko Rika

Analisis: Pada data di atas kata Rikamartdikatakansalahsebab kata mart seharusnya diganti dengan kata "toko" karena kata "mart" memiliki padanan yang berarti toko. 


\section{Data 2}

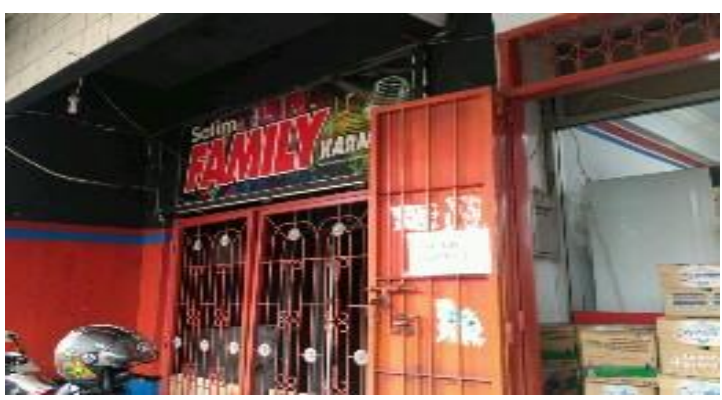

Salah: Salim Family Karaoke

Benar: Salim Karaoke keluarga

Analisis: pada data di atas sepenuhnya menggunakan Bahasa Inggris.

Data 3

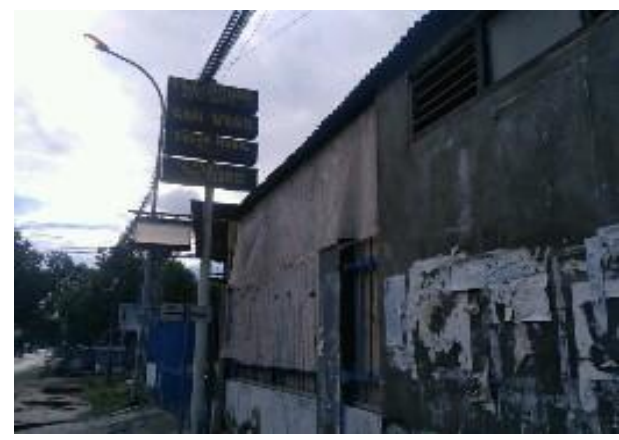

Salah: Falminggo Car Wash

Benar: pencucian Mobil Flaminggo

Analisis: data di atas dinyatakan salah sebab menggunakan bahasa Inggris, harusnya menggunakan bahasa Indonesia karena memiliki arti Pencucian mobil Flaminggo.

\section{Data 4}

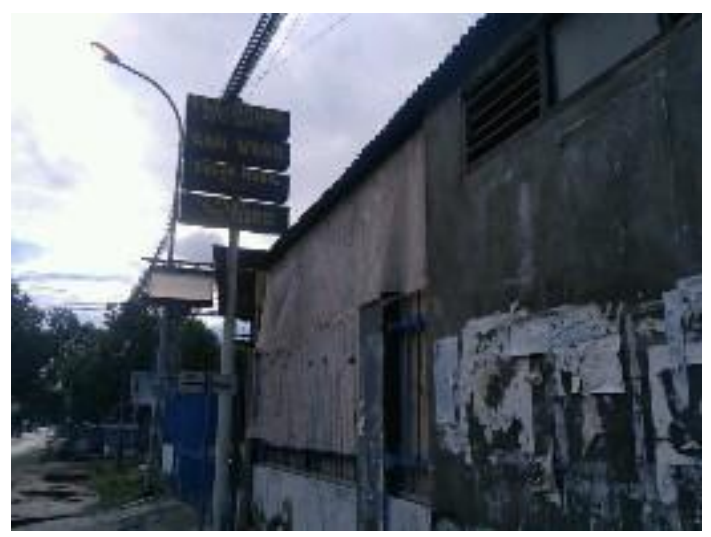

Salah: Poles Body, interior, engine

Benar: poles tubuh, hiasan ,mesin.
Analisis: data di atas dinyatakan salah sebab menggunakan bahasa Inggris.

Data 5

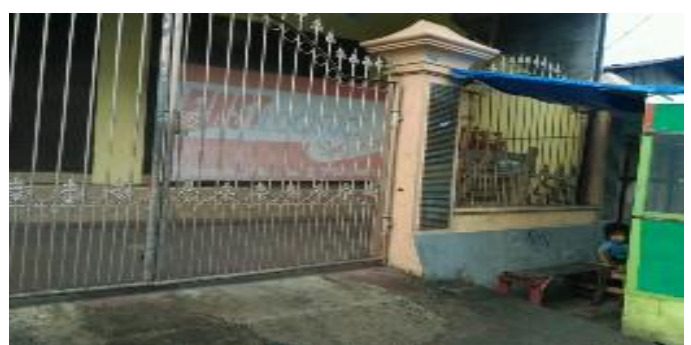

Salah: First logistics

Benar: logistic pertama

Analisis: dinyatakan salah sebab menggunakan bahasa Inggris

\section{Data 6}

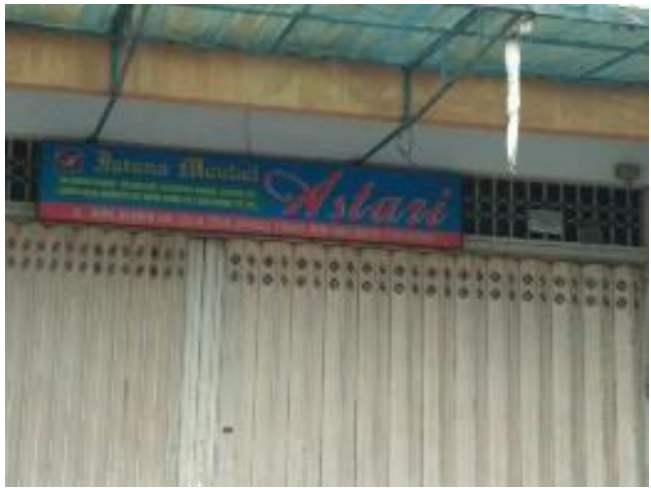

Salah: Istana meubel Astari

Benar: Istana mebel Astri

Analisis: pada data tujuh di atas kesalahan terdapat pada kata meubel. Menurut KBBI kata meubel ditulis mebel yang berarti perabot rumah/ruangan.

Data 7

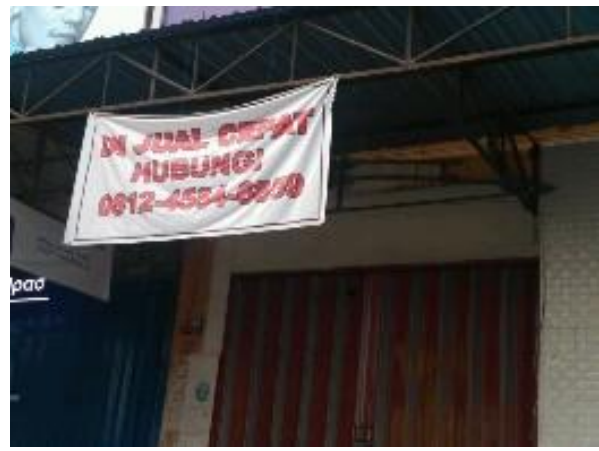

Salah: DI JUAL CEPAT HUBUNGI

Benar: DIJUAL CEPAT HUBUNGI 
Analisis: pada data tujuh di atas dinyatakan salah sebab kata "di" bukan termasuk preposisi dan harus ditulis terpisah, menurut PUYD preposisi ditulis terpisah dengan kata dasar yang dilekatinya jika menunjukkan tempat atau arah. Seharunya kata di tidak ditulis terpisah.

\section{Data 8}

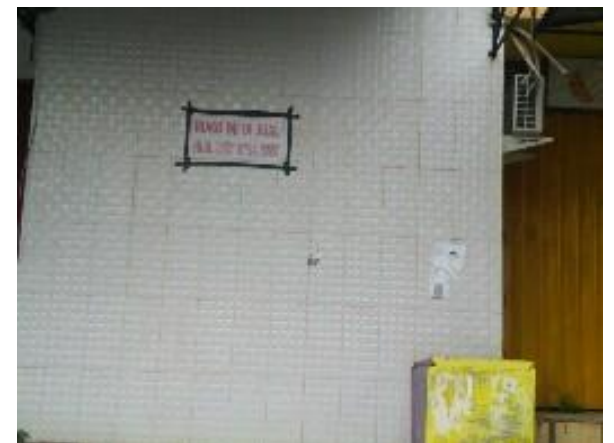

Salah: Ruko ini di jual

Benar: Ruko ini dijual

Analisis: data 8 dinyatakan salah yaitu pada kata di. Kata di seharusnya melekat dengan kata jual. Sebab kata di bukan merupakan preposisi.

Data 9

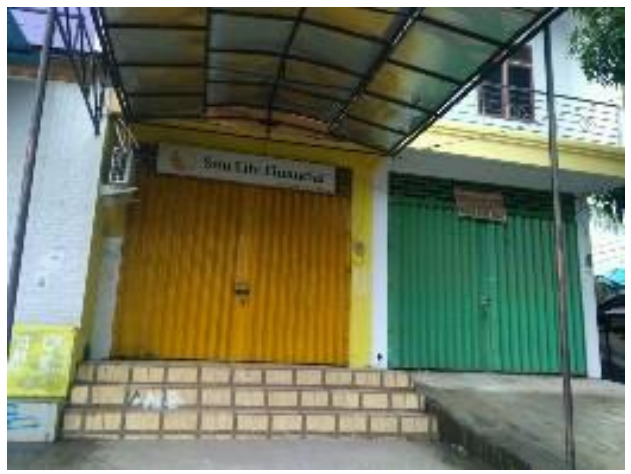

Salah: sun life financial

Benar: keuangan hidup matahari

Analisis: data sembilan dinyatakan salah, sebab seutuhnya menggunakan bahasa Inggrisnya. Seharusnya ditulis menggunakan bahasa Indonesia karena menjadi papan nama sebuah kantor.

\section{Data 10}

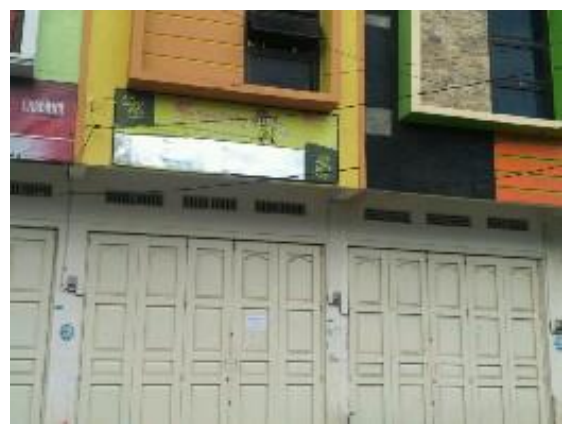

Salah: super wash

Benar: mencuci super

Analisis: dinyatakan salah, sebab seutuhnya menggunakan bahasa Inggris. Seharusnya ditulis menggunakan bahasa Indonesia karena menjadi papan nama sebuah tempat usaha.

\section{Data 11}

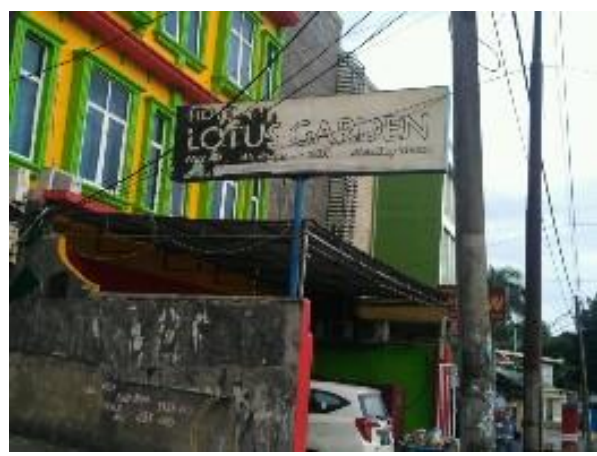

Salah: Hotel Lotus Garden

Benar: Hotel taman Lotus

Analisis: dinyatakan salah, sebab seutuhnya menggunakan bahasa Inggris. Seharusnya ditulis menggunakan bahasa Indonesia karena menjadi papan nama sebuah hotel yang berada di tengah kota.

\section{Data 12}

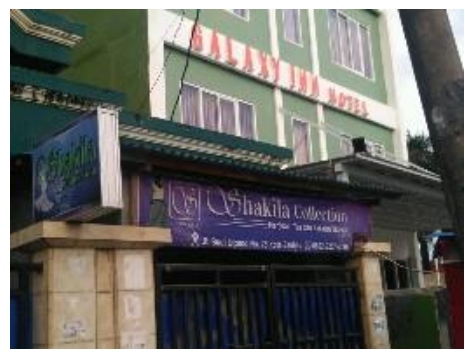

Salah: Galaxy inn Hotel

Benar: Hotel galaksy Inn 
Analisis: dinyatakan salah, sebab seutuhnya menggunakan bahasa Inggris. Seharusnya ditulis menggunakan bahasa Indonesia karena menjadi papan nama sebuah hotel yang berada di tengah kota.

\section{Data 13}

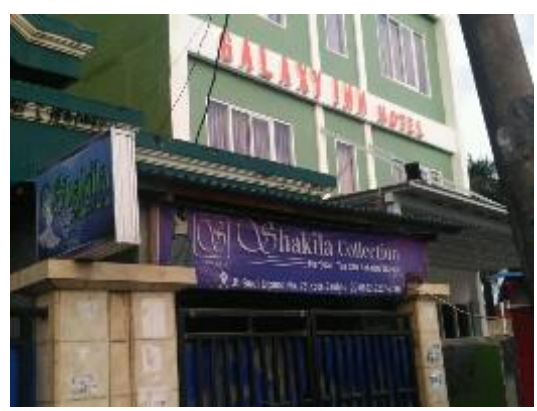

Salah: Shakila Collection

Benar: KoleksiShakila

Analisis: dinyatakan salah, sebab seutuhnya menggunakan bahasaInggris. Seharusnya ditulis menggunakan bahasa Indonesia karena menjadi papan nama sebuah toko.

\section{Data 14}

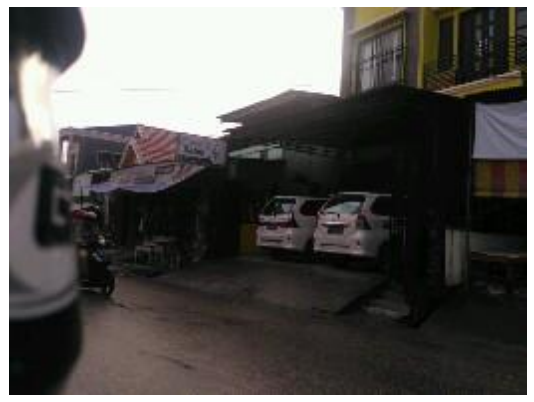

Salah: King's Salon

Benar: Salon King's

Analisis: dinyatakan salah, sebab seutuhnya menggunakan Bahasa Inggris. Seharusnya ditulis menggunakan bahasa Indonesia.

\section{Data 15}

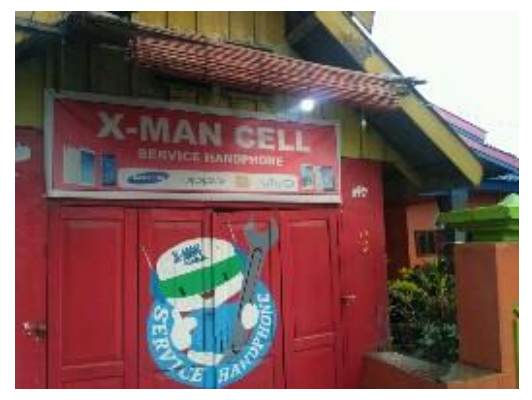

Salah: Service handphone

Benar: servis telepon genggam

Analisis: dinyatakan salah, sebab seutuhnya menggunakan bahasa Inggris. Seharusnya ditulis menggunakan bahasa Indonesia.

\section{Data 16}

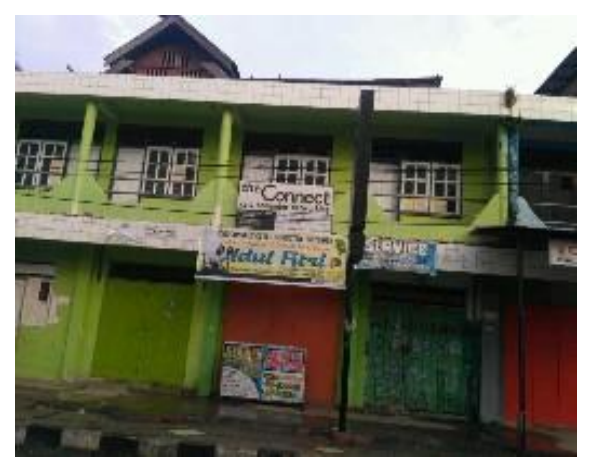

Salah: The Connect cctv-computernetworking

Benar: tersambung cctv-komputerjaringan

Analisis: dinyatakan salah, sebab seutuhnya menggunakan Bahasa Inggris. Seharusnya ditulis menggunakan bahasa Indonesia.

\section{Data 17}

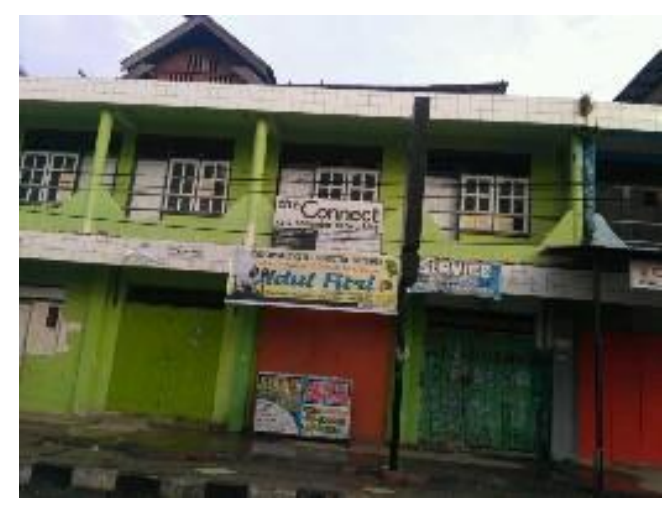

Salah: service handphone laptop \&Computer

Benar: memperbaiki telepon genggan dan komputer

Analisis: dinyatakan salah, sebab seutuhnya menggunakan Bahasa Inggris. Seharusnya ditulis menggunakan bahasa Indonesia. 


\section{Data 18}

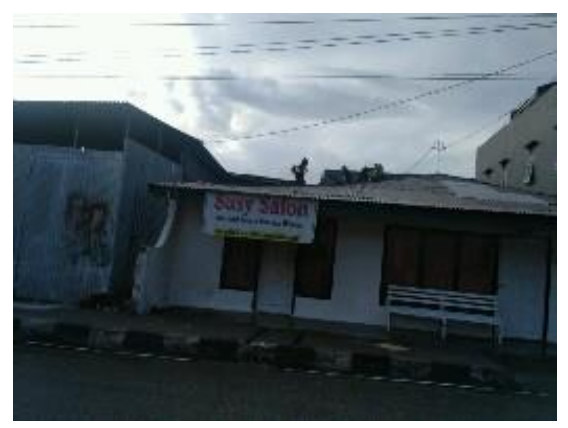

Salah: susy salon hair and beauty priadanwanita

Benar: salon susy kecantikan, rambut pria dan wanita

Analisis: data di atas dinyatakan salah sebab tidak menggunakan bahasa Indonesia sepenuhnya.

\section{Data 19}

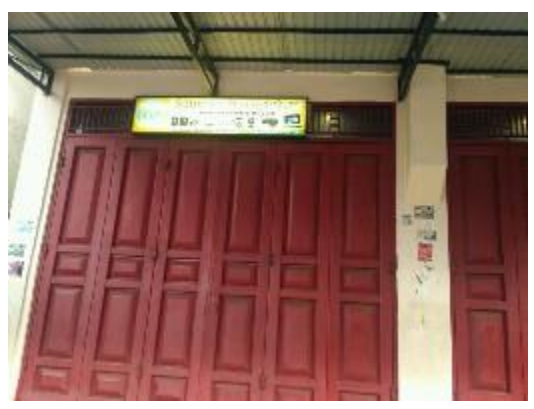

Salah: Naura Computer sale, service \& kredit

Benar: Komputer Naura, menjual, servis(memperbaiki) \& kredit

Analisis: dinyatakan salah sebab menggunakan bahasa Inggris sebagai papan nama tempat usaha.

\section{Data 20}

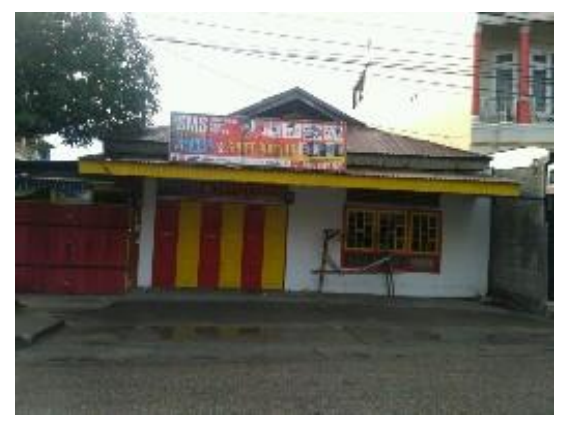

Salah: smartphone mobile solution

Benar: solusi telepon genggam
Analisis: dinyatakan salah sebab menggunakan bahasa Inggris sebagai papan nama tempat usaha.

\section{Data 21}

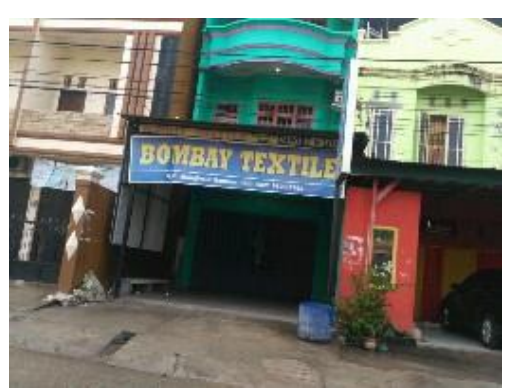

Salah: Bombay textile

Benar: tekstil Bombay

Analisis: data diaatas dinyatakan salah sebab menggunakan bahasa Inggris dan struktur kalimat dalam bahasa Inggris dalam papan nama tempat usaha.

\section{Data 22}

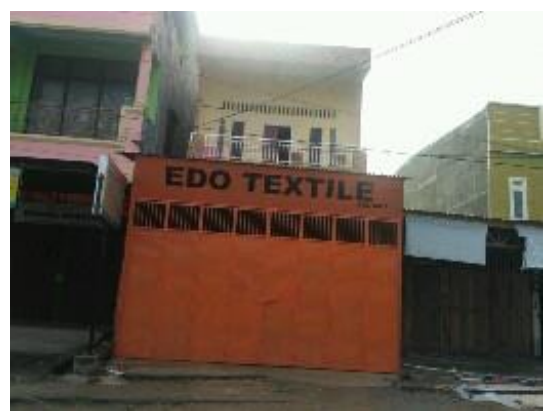

Salah: edo textile

Benar: Tekstil Edo

Analisis: data 22 dinyatakan salah atau kurang tepat sebab menggunakan bahasa Inggris dan struktur kalimat dalam bahasa Inggris dalam papan nama tempat usaha.

\section{Data 23}

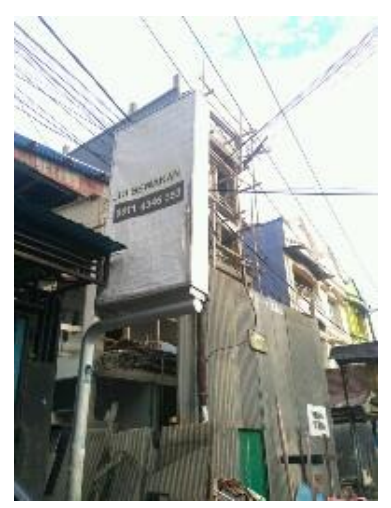




\section{Salah: DI SEWAKAN}

\section{Benar: DISEWAKAN}

Analisis: data 23 dinyatakan salah atau kurang tepat penulisannya. Kesalahan terjadi pada kata di yang ditulis terpisah dengan kata yang dilekatinya. Seharusnya kata di ditulis bersambung dengan kata yang dilkatinya. Kata di sebagai preposisi ditulis terpisah apabila kata yang dilekatinya adalah penunjuk arah atau tempat, sementara pada data 23 kata sewakan bukan menunjukkan tempat atau arah, jadi harus ditulis bersanbung menjadi disewakan.

\section{Data 24}

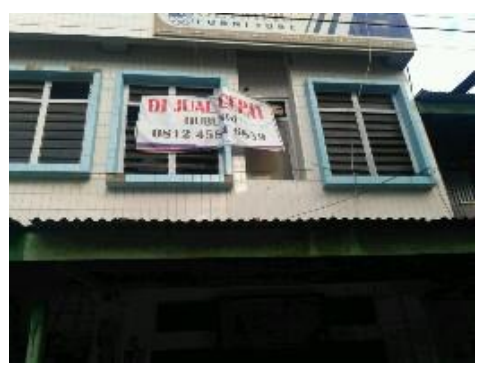

Salah: DI JUAL CEPAT

\section{Benar: DIJUAL CEPAT}

Analisis: data 24 dinyatakan salah atau kurang tepat penulisannya. Kesalahan terjadi pada kata di yang ditulis terpisah dengan kata yang dilekatinya. Seharusnya kata di ditulis bersambung dengan kata yang dilkatinya. Kata $d i$ sebagai preposisi ditulis terpisah apabila kata yang dilekatinya adalah penunjuk arah atau tempat, sementara pada data 24 kata jual bukan menunjukkan tempat atau arah, jadi harus ditulis bersambung menjadi dijual cepat.

\section{Data 25}

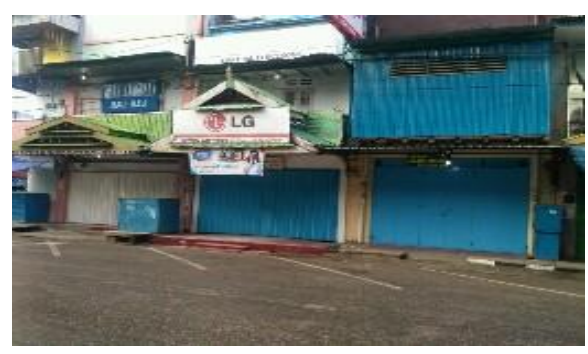

Salah: central electronic

Benar: sentral/pusat elektronik
Analisis: data 25 kurang tepat dijadikan sebagai papan nama sebuah toko elektronik sebab menggunakan bahasa Inggris sepenuhnya.

Berdasarkan peraturan yang dijabarkan di atas maka dapat kita katakan bahwa data di atas terlihat adanya beberapa bentuk kesalahan yang muncul, pertama penulisan kata dan preposisi yang tidak tepat, seperti pada data ke-8, data ke-9, data ke-23, data ke-24. Terjadinya kesalahan ini diakibatkan ketidakpahaman pemakai bahasa terhadap aturan penulisan pemakaian preposisi dan imbuhan.

Kesalahan kedua terlihat pada penggunaan bahasa Inggris seutuhnya pada papan nama, toko, restoran, hotel, dan salon. Penulisan tidak sesuai dengan peraturan (baca: Undang-Undangbahasa) yang berlaku. Sepertiterlihatpada data ke-1, ke-2, ke-3, ke-4, ke-5, ke-6, ke-7, ke-10, ke-11,ke-12, ke13,ke-14, ke-15, ke-16, ke-17, ke-18, ke-19, ke-20, ke-21, ke-22, ke-25.

Kesalahan penggunaan bahasa Indonesi di ruang publik atau media luar di kota Baubau paling banyak terjadi pada penulisan bahasa Inggris. Hal ini disebabkan oleh adanya pemikiran bahwa penggunaan bahasa Inggris pada papan nama tempat usaha, atau petunjuk umum atau tempat-tempat lainnya dapat menimbulkan kesan bahwa bahasa Inggris lebih berwibawa dibandingkan dengan bahasa Indonesia, padahal mayoritas penduduk kota Baubau menggunakan bahasa Indonesia selain bahasa daerah dalam berkomunikasi sehari-hari.

Adapun yang menjadi faktor-faktor penyebab terjadinya kesalahan bahasa Indonesia di ruang publik yang ada di kota Baubau adalah yang pertama kurangnya pengetahuan tentang kaidah penulisan bahasa Indonesia yang baik dan benar sesuai kaidah bahasa Indonesia yang disempurnakan. Kedua tidak adanya sangsi nyata bagi pelanggaran penulisan.Ketiga kurangnya kesadaran akan pentingnya menggunakan bahasa Indonesia yang baik dan benar di ruang publik. 


\section{KESIMPULAN}

Penggunaan dan penguasaan bahasa asing memang perlu di zaman sekarang ini namun ada baiknya jika dibarengi dengan penguasaan bahasa Indonesia bukan hanya secara lisan saja namun secara tertulis. Terlebih yang sifatnya untuk dibaca orang banyak. Tidak ada salahnya menggunakan bahasa Inggris di zaman sekarang ini apalagi untuk menyiapkan bangsa Indonesia ke arah indistri 4.0, namun baiknya tidak harus menginternasionalisasikan segala aspek termasuk dalam hal bahasa, sebab bahasa Indonesia adalah ciri, lambang, kebanggan, dan identitas masyarakat Indonesia. Jika hal ini dibiarkan secara terus-menerus tidak dapat dibayangkan generasi selanjutnya tidak akan ada lagi rasa memiliki dan bangga terhadap bahasa Indonesia.

Menurut hemat penulis, kesalahankesalahan seperti ini akan terus terjadi karena tidak adanya sangsi bagi pelanggar. Selama ini yang terjadi baru sebatas upaya sosialisasi di kantor-kantor. Menyikapi persoalan ini maka diperlukan upaya semacam solusi strategis untuk mengurangi banyaknya kesalahan yakni salah satunya adalah melalui pembelajaran bahasa dan sastra Indonesia di sekolahsekolah dari tingkat sekolah dasar hingga tingkat menengah atas, sosialisasi tingkat universitas melalui mahasiswa pendidikan bahasa dan sastra Indonesia, serta memberlakukan sangsi bagi setiap pelanggar. Hal ini perlu dilakukan agar bahasa Indonesia memiliki wibawa dan sebagai lambag identitas yang wajib digunakan oleh masayarak Indonesia.

\section{DAFTAR PUSTAKA}

Arifin, EZ, \& Tasai A. (2010). Cermat Berbahasa Indonesia untuk Perguruan Tinggi. Jakarta: Akademika Pressindo.

Finoza, L. (2001). Komposisi Bahasa Indonesia. Jakarta: InsanMulia.
Hidayati, I. (2012). BukuPintar EYD. Yogyakarta: Indonesia Tera.

https://indahqonieeth.wordpress.com/2011 /04/12/kesalahan-berbahasa-danproses-terjadinya-kesalahanberbahasa/

Parera, OD. (1997). Linguistik Educational. Jakarta: Erlangga.

Rahman, F. (2018). The Constraints of Foreign Learners in Reading English Literary Works: A Case Study at Hasanuddin University. Journal of Arts and Humanities, 7(2), 01-12. DOI:

http://dx.doi.org/10.18533/journal .v7i2.1327

Sugono, D. (1999). Berbahasa Indonesia denganBenar. EdisiRevisi. Jakarta: Puspaswara.

Undang-Undang Republik Indonesia Nomor 24 Tahun 2009 tentangBendera, Bahasa, dan Lambang Negara, serta Lagu Kebangsaan. 